\title{
Algebraic competences and emotional intelligence of first year Bachelor of Science in Mathematics and Science Education students at the Copperbelt University in Zambia
}

\author{
Allan Musonda* \\ doi: http://dx.doi.org/10.18543/tjhe-5(1)-2017pp171-195
}

\begin{abstract}
This study examined the relationship between algebraic competences and emotional intelligence of first year Bachelor of Science in mathematics and science education students at Copperbelt University in Zambia. All (143) first year Bachelor of Science in mathematics and science education students, in 2016, were purposively selected for the study. The study was motivated by evidence that students generally do not perform well in their first year university mathematics examinations despite the students having very good university entry grades in secondary school mathematics. This poor academic performance may be due to many factors. However, this study identified and focused on emotional intelligence as one such factor. Emotional intelligence is defined as the ability to identify, assess and manage the emotions of one's self, of others and of groups. It is argued that emotional intelligence represents an ability to reason with emotions and to use emotions to facilitate thought. On the other hand, Algebra was chosen as the focus of the study because of its centrality to the whole of first year university mathematics content. Algebra is found in all branches of mathematics directly or indirectly. Therefore, the study explored the algebraic competences of the first year students and examined possible relationships with their emotional intelligence. Emotional intelligence was measured using the Schutte SelfReport Emotional Intelligence Test (SSEIT), and algebraic competences were measured through a Grade 12 level algebra achievement test and a university level algebra achievement test constructed by the researcher. Data were analysed using nonparametric statistical techniques: Spearman's Rank Order Correlation (rho) and the Mann-Whitney U Test. Results showed that there is a significant positive correlation between Grade 12 level and first year university level algebraic competences. Results also showed that there is no significant relationship between students' algebraic competences and their emotional intelligence. Furthermore, the study reviewed that female students have higher levels of emotional intelligence than their male counterparts.
\end{abstract}

\footnotetext{
Allan Musonda (allanmusondak@yahoo.co.uk) is Lecturer (II) of Mathematics Education at the Copperbelt University in Zambia.

More information about the authors is available at the end of this article (after the bibliography list).
} 
Keywords: algebraic competences; emotional intelligence; emotions; facilitate thought; mathematics and science education students; algebra.

\section{Introduction}

Every institution of learning whether at primary, secondary or tertiary level, is concerned with the academic achievement of its learners. ${ }^{1}$ It is the concern of institutions of learning that their learners progress from one level to another and are able to complete whatever programme they are in within the specified time period. Thus learners are expected to express levels of competence in what they are learning in order to move to a higher level. In many situations, however, this is not the case as learners do not progress from one level to another due to poor academic achievement. ${ }^{2}$ Poor academic achievement of learners is due to many factors, among which is emotional intelligence. Scholars have pointed out that learners' emotional intelligence is one of the factors that determine the achievement of learners. ${ }^{3}$

A number of studies on emotional intelligence and academic achievement have been conducted in tertiary institutions of learning both in Africa and outside. For instance, a study ${ }^{4}$ conducted in Malaysia examined the effect of emotional intelligence on academic performance of first and final year medical students. A total of 163 (84 year one and 79 year five) medical students participated in this study and the Mayer-Salovey-Caruso Emotional Intelligence Test (MSCEIT) was used to measure emotional intelligence of the participants. The researchers found that emotional intelligence was a significant predictor of academic performance in overall continuous assessments and final examination amongst the first- and final-year medical students. ${ }^{5}$

A study ${ }^{6}$ was conducted in Dubai, in 2014, to determine the impact of emotional intelligence on academic achievements of expatriate college students in that country. In this study, the researcher observed that expatriate

${ }^{1}$ Poonam Mishra, "A Study of the Effect of Emotional Intelligence on Academic Achievement of Jaipur Senior Secondary Students," International journal of Educational Research and Technology 3, no. 4 (2012).

${ }^{2}$ Mishra, "A Study of the Effect of Emotional Intelligence."

${ }^{3}$ Sean McPheat, Emotional Intelligence (London: Ventus Publishing Apps, 2010).

${ }^{4}$ Boon H. Chew et al., "Emotional intelligence and academic performance in first and final year medical students: a cross-sectional study," BMC Medical Education 13 (2013): 44.

${ }^{5}$ Boon H. Chew et al., "Emotional intelligence and academic performance."

${ }^{6}$ Aruna Kolachina, "Impact of Emotional Intelligence on Academic Achievements of Expatriate College Students in Dubai," International Journal of Social Science and Humanities Research 2, no. 2 (2014): 102. 
students with positive emotional intelligence traits succeeded in academic achievement, whereas expatiate students with negative emotional intelligence traits failed in gaining academic achievements. The tool used for data collection, in this study, was a structured questionnaire, which covered the demographic profile of students, their academic achievement and their perception on emotional intelligence. This tool was in the researcher's view not adequate to measure emotional intelligence since it only provided for students' perception on their emotional intelligence.

Another study investigating the relationship between emotional intelligence and academic achievement among undergraduate university students is that conducted at the University of the West Indies (UWI), Barbados. ${ }^{7}$ The study investigated the relationships between emotional intelligence and academic achievement among 151 undergraduate psychology students. The instruments used in this study are Barchard's Emotional Intelligence Scale and an Academic Achievement Scale. The researcher found significant positive correlations between academic achievement and six of the emotional intelligence components. In this study since the Academic Achievement Scale was a 50-item multiple choice test, it is possible that some students might have resorted to guessing answers to questions which were not known. A test in which students showed their thinking by writing out explanations as solutions could have been ideal.

In 2011 a study to examined the role of emotional intelligence in college students' success was conducted in Florida. ${ }^{8}$ The participants in this study were studentsenrolled in an Introduction to Business course at a large state college in Florida. The Bar-On 2004 (Emotional Quotient Inventory) EQ-i with 133-items was used to assess students' emotional intelligence. Results revealed that there was a slight positive correlation between traditional measures of academic success (GPA, attempted-to-completed credit hour ratio, grade in the course) and emotional intelligence.

The sample of research studies show the positive relationship between emotional intelligence and academic achievement in a number of first year university courses. A lot of the studies examined were outside Africa, and therefore cultural context cannot be ruled out in the relationship between emotional intelligence and academic achievement. It is important to ascertain if similarfindings would be found in a different cultural setting. This paper

7 Grace A. Fayombo, "Relating emotional intelligence to academic achievement among university students in Barbados," The International Journal of Emotional Education 4, no. 2 (2012): $43-54$.

${ }^{8}$ Joyce G. Walsh-Portillo, "The Role of Emotional Intelligence in College Students' Success" (PhD diss., Florida International University, 2011). 
examines the relationship between emotional intelligence and algebraic competences of first year Bachelor of Science in mathematics and science education students at Copperbelt University in Zambia, Africa.

\section{Statement of the problem and research purpose}

Mathematics is one of the key subjects in the study of natural sciences including engineering, technology, and business related studies. At Copperbelt University in Zambia, every student admitted into first year, regardless of the programme they wish to pursue, is required to do first year mathematics. Thus mathematics, at first year level is compulsory to all schools of the university at undergraduate level. Even though first year mathematics is emphasised so much in the university, the performance of the students in the mathematics course at first year is not good. According to the university records, and my observation as a lecturer teaching first year mathematics over a period of four (4) years, it has been observed that more than $30 \%$ of education students fail first year mathematics (MA 120) every year with some students repeating it twice and in some cases thrice. In particular, the Examiners' Reports for the past four consecutive years $(2012,2013,2014$ and 2015) have indicated that $43 \%, 47 \%, 39 \%$ and $34 \%$ respectively of first year Bachelor of Science in mathematics and science education students failed MA 120. This is not positive as students who fail end up being delayed in their academic programmes. The delay results in students not being able to graduate on time and serve the nation in various capacities of their careers. Furthermore, other students do not even graduate as they are excluded from the university along the way due to their poor performance in the course.

This situation raises a number of questions, more especially that these students are admitted to the University because they passed their Ordinary level mathematics (secondary school mathematics) with good grades (a merit or better). That being the case, students then have the cognitive intelligence to make it in first year university mathematics in general and algebra in particular. However, there seem to be factors influencing the achievement of students while at university. It is argued that these factors "go beyond academic intelligence capabilities and cover a wide range of issues such as loneliness, loss of the peer support group from high-school, relationship break-ups, and financial difficulties." The researcher's argument is that these factors have

9 James D. A. Parker, Donald H. Saklofske, and Con Stough,ed., Assessing Emotional Intelligence - Theory, Research, and Applications (New York: Springer, 2009). 
something to do with students' emotions. As such the students' emotional intelligence might be one of the factors influencing academic achievement in mathematics. Thus, this research was aimed at establishing the relationship between algebraic competences and emotional intelligence of first year Bachelor of Science in mathematics and science education students' at Copperbelt University in Zambia. Algebra was chosen because it spreads throughout all other branches of first year university mathematics and it is taught in the first term of the academic year at the university.

\section{Research questions}

The following questions guided the study:

1. Is there any correlation between the Grade 12 level Algebraic competences and the First year university level Algebraic competences of first year Bachelor of Science in mathematics and science education students as measured by the Grade 12 level Algebra test and the First year university level Algebra test?

2. Is there a significant relationship between Grade 12 level algebra test scores and emotional intelligence scores of first year Bachelor of Science in mathematics and science education students?

3. Is there a significant relationship between first year Bachelor of Science in mathematics and science education students' university algebra test scores and their emotional intelligence scores as measured by the SSEIT?

4. Is there a significant difference between male and female first year Bachelor of Science in mathematics and science education students in their emotional intelligence as measured by the SSEIT?

\section{Competences and emotional intelligence}

\section{III.1. Competences}

Competences refer to skills, knowledge, understanding and abilities we possess. ${ }^{10}$ Competences can generally be divided into two: generic competences

${ }^{10}$ Aurelio Villa Sánchez and Manuel Poblete Ruiz, eds., Competence -based learning: A proposal for the assessment of generic competences (Bilbao: University of Deusto, 2008). 
and subject specific competences. Generic competences are those competences which every student, regardless of their chosen field should possess.

Generally every university graduate is expected to be able to translate knowledge into practice and to apply knowledge to new situations. ${ }^{11}$ University graduates should be able to work independently or with minimum supervision, and should at the same time be able to work with other people in intra and intercultural and/or international environments. ${ }^{12}$ In this $21^{\text {st }}$ century, university graduates should have practical cost effective problem solving techniqueswhile possessingthe capacity to use innovative and appropriate technologies, for example; the use of a computer by demonstrating ability to use basic computer packages such as Microsoft Word, Excel and use of Email.

Apart from generic competences which apply to all university graduates, there are subject specific competences. Subject specific competences are those competences that are unique to a particular programme. For instance, all Bachelor of Science in mathematics and science education students at Copperbelt University in Zambia, are on a programme - the teacher education programme. There are specific skills and abilities expected from every student on this programme upon completion. The abilities and skills of teacher education graduates include: ability to prepare schemes of work, ability to prepare lesson plans, ability to identify suitable methods of teaching for different topics and different contexts, ability to teach secondary school students using different methods of teaching, ability to assess students using different ways of assessment, ability to manage their classes, ability to monitor students` progress and ability to record work done during the teaching and learning sessions. ${ }^{13}$ Teacher education graduates are expected to be able to create a learning environment conducive to promoting learning. Furthermore, graduates on a teacher education programme are expected to have interpersonal competences which help them to be sensitive to the feelings of others and to collaborate and network with other people: their peers, head teachers, parents, professional groups and any other stake holders in the field of education. ${ }^{14}$

In teacher education programmes, two sets of subject-specific competences need to be developed; those that permit graduates to work as teachers and those that permit them to become specialists in a chosen area of

${ }^{11}$ Karola Hahn and Damtew Teferra, "Tuning as Instrument of Systematic Higher Education Reform and Quality Enhancement: The African Experience," Tuning Journal of Higher Education 1, no. 1(2013): 127-158.

${ }_{12}$ Ibid.

13 Julia González and Robert Wagenaar, eds., Tuning Educational Structures in Europe II. Universities' Contribution to the Bologna Process (Bilbao: Universidad de Deusto, 2005).

${ }^{14}$ Hahn and Teferra, "Tuning as Instrument of Systematic Higher Education," 127-158. 
teaching, for example mathematics. At Copperbelt University, in Zambia, for instance, Bachelor of Science in mathematics and science education students have to choose one specific subject specialization from four areas namely: Biology, Chemistry, Mathematics and Physics. The subject specialization under consideration in this research is Mathematics. Within the mathematics area of specialization, there are competences which every student of Mathematics is expected to demonstrate both before and after graduation.

\section{III.2. Algebraic competences}

Algebra, as a branch of mathematics, has its own competences, and those competences are related to the rest of mathematics. Some of the Algebraic competences at both Grade 12 and university levels expected of students, in Zambia, ${ }^{15}$ include:

1. Ability to solve quadratic equations using different types of methods e.g. Factorization, completing the square etc.

2. Ability to factorise higher order polynomials by first factoring out a common power of the variable. For example the question: Solve the equation $x^{4}-29 x^{2}+100=0$.

3. Capacity to manipulate algebraic rational expressions by decomposing them into partial fractions. For example the question: Decompose $\frac{2 x+3}{x^{2}-7 x+6}$ into partial fractions.

4. Ability to translate word problems involving one or several variables into equations (or inequalities) and solve them.For instance the question: Tickets are being sold for a film show. Tickets for adults cost K50 each while tickets for children are sold at half the cost of an adult ticket each. How many tickets of each kind were sold if a total of 200 tickets were sold and a total of K6, 000 was collected (let $\mathrm{x}$ be the number of tickets for adults and $y$ the number of tickets for children)

5. Ability to simplify algebraic rational expressions. For example the question, simplify $\frac{2 x^{2}-9 x+10}{5 x^{2}-20}$.

15 Ministry of Education (MoE), “O” Level Mathematics Syllabus (Grades 10 - 12) (Lusaka: Curriculum Development Centre, 2012). 
6. Capacity to work with different functions and be able to manipulate them. For example the question: If the function $f(x)=5+\frac{x}{2}$ and $g(x)=$ $=3 x+2$, find the value of $x$ for which $f^{-1}(x)=g(x)$.

The above mentioned algebraic competences are not just unique to Zambia. Algebra is universal. Students from different countries around the world learn the same algebraic concepts, principles and skills. ${ }^{16}$

Apart from algebra mathematics has other branches, which include: arithmetic, geometry, trigonometry, calculus etc. We find that algebraic competences are needed in other branches of mathematics. For instance, here is a question and solution on trigonometric identities at first year university.

\section{Question:}

Find all the possible values of $\theta$ in the equation $\cos ^{2} \theta-3 \sin \theta+3=0$, given that $0^{\circ} \leq \theta \leq 360^{\circ}$.

\section{Solution:}

We proceed to find the values by first ensuring that $\cos ^{2} \theta$ and $\sin \theta$ in $3 \sin \theta$ are expressed in similar terms. Taking the identity $\cos ^{2} \theta+\sin ^{2} \theta=1$, we make $\cos ^{2} \theta$ the subject of the formula so that we obtain $\cos ^{2} \theta=1-\sin ^{2} \theta$. We take the trigonometric equation $\cos ^{2} \theta-3 \sin \theta+3=0$ and replace $\cos ^{2} \theta$ in this equation with $1-\sin ^{2} \theta$ so that we have $1-\sin ^{2} \theta-3 \sin \theta+3=0$. At this point we notice that we have expressed the terms in terms of $\sin \theta$, we now need to $\operatorname{simplify}$ the equation to obtain $-\sin ^{2} \theta-3 \sin \theta+4=0$ which is the same as $\sin ^{2} \theta+3 \sin \theta-4=0$ obtained by multiplying the equation throughout by negative 1 . We remember that multiplying or dividing the terms of an equation throughout by the same number does not change the equation. It remains the same equation. Having obtained $\sin ^{2} \theta+3 \sin \theta-4=$ 0 we may notice that this resembles a kind of equations called quadratic equations so we let a letter say $x=\sin \theta$ so that $x^{2}=(\sin \theta)^{2}=\sin ^{2} \theta$. We then make replacements in the equation $\sin ^{2} \theta+3 \sin \theta-4=0$, that is $x^{2}+3 x-4=$ 0 . The equation is then solved by factorization as outlined below:

$$
\begin{gathered}
x^{2}+3 x-4=0 \\
x^{2}+4 x-x-4=0 \\
x(x+4)-1(x+4)=0 \\
(x+4)(x-1)=0
\end{gathered}
$$

${ }^{16}$ Frederick K.S. Leung et al., Algebra Teaching around the World (Rotterdam: Sense Publishers, 2014). 


$$
\begin{gathered}
(x+4)=0 \text { or }(x-1)=0 \\
x=-4 \text { or } x=1
\end{gathered}
$$

But $x=\sin \theta$ then $\sin \theta=-4$ or $\sin \theta=1$.

We discard $\sin \theta=-4$ since $-1 \leq \sin \theta \leq 1$ and we remain with $\sin \theta=1$

Then $\sin \theta=1$

$$
\begin{gathered}
\theta=\sin ^{-1}(1) \\
\theta=90^{\circ}
\end{gathered}
$$

In this trigonometry problem, algebraic competences are needed. Competences needed include the following:

1. Ability to express terms in an expression or equation in similar terms.

2. Ability to express one term as the subject of the formulae of the other.

3. Ability to make substitutions

4. Ability to simplify mathematical expressions

5. Ability to solve quadratic equations

Possession of these competences is affected by many factors. In this study the researcher isolated emotional intelligence as one such factor that may affect the acquisition of algebraic competences by students. This decision was arrived at by the researcher based on studies done earlier by other researchers who assert that emotional intelligence is a factor that predicts academic achievement. ${ }^{17},{ }^{18},{ }^{19}$

\section{III.3. Emotional intelligence}

Emotional Intelligence is defined as the ability to identify, assess and manage the emotions of one's self, of others and of groups.$^{20}$ It is argued that emotional intelligence represents an ability to reason with emotions and to

17 Joseph C. Adigwe," Emotional Intelligence and Problem- Solving Achievement of Chemistry Students,"Journal of Science, Technology \& Education 3, no. 1 ( 2015):80.

18 Yoke Theing Chen and Chooi Seong Lai, "Personality Traits, Emotional Intelligence and Academic Achievements of University Students," American Journal of Applied Psychology 4, no. 3 (2015): 39-44.

${ }^{19}$ Rosalind M. Prabha, "Emotional intelligence as a correlate of academic achievement among first year degree students in Puducherry," International Journal of Research in Social Sciences 3, no. 6 (2015): 259-263.

${ }^{20}$ Susan Chirayath and Nancy G. Elizabeth, "Influence of Emotional Intelligence on Learning Styles-An Exploratory Study on Management Students,"Journal of Business Management \& Social Sciences Research 2, no. 3 (2013): 2319-5614. 
use emotions to facilitate thought. A number of scholars and researchers are associated with development of the concept of emotional intelligence. These include: Howard Gardner, Wayne Payne, John Mayer, Peter Salovey and David Goleman.

\section{Theoretical framework of emotional intelligence}

The concept of emotional intelligence has roots in past research and practice of early scholars who believed that emotional intelligence should be understood in the context of all that makes up human intelligence and not in isolation. Scholars indicate that as early as the 1920s a psychologist named Thorndike theorized that there were three types of intelligence: social, mechanical and abstract. It is argued that Thorndike used the term "social intelligence" to describe the skill of understanding and managing other people. ${ }^{21}{ }^{22}$ Social intelligence is said to be "the ability to understand other people, what motivates them, how they work, how to work with them and the ability to act wisely in the relationship between human beings." ${ }^{23}$ Furthermore, it is argued that self-awareness, empathy, and dealing with interpersonal relationships, which are at the centre of emotional intelligence, are the basic elements of social intelligence. ${ }^{24}$ In 1940 David Wechsler added to the concept of non - cognitive intelligence by arguing that "no full definition of intelligence could exist until we were able to fully define those aspects that were not related to traditionally measured cognitive skills." ${ }^{25}$ In 1983 , Howard Gardner advanced the theory of Multiple Intelligences in his book entitled "Frames of Mind; The Theory of Multiple Intelligences."He argued that people have more than one type of intelligence, and these types of intelligence were also cognitive in nature but could not fully be defined by a model such as the standard intelligent quotient (IQ) tests.Gardner's model for multiple intelligences focused mainly on two aspects:

i) Intrapersonal intelligence, which is the ability to understand one's own feelings, motivations and fears and

${ }^{21}$ Mc Pheat, Emotional Intelligence.

${ }_{22}$ Olivier Serrat, Understanding and Developing Emotional Intelligence (Washington, DC: Asian Development Bank, 2010).

${ }^{23}$ Azizi Yahaya et al., "The Impact of Emotional Intelligence Element on Academic Achievement," Journal of Archives Des Sciences 65, no.4 (2012): 3

${ }^{24}$ Yahaya et al., "Impact of Emotional Intelligence Element on Academic Achievement."

${ }^{25}$ Mc Pheat, Emotional Intelligence, 9. 
ii) Interpersonal intelligence, which is the ability to understand others and their desires, motivations and intentions.

The term emotional intelligence was first used in 1985 by a doctoral student Wayne Payne in his thesis, "A Study of Emotion: Developing Emotional Intelligence.” In 1990, two psychologists Peter Salovey and John Mayer for the first time defined emotional intelligence as the ability of a person to cope with his/her emotions and later in 1995, Goleman attracted so much public attention through his book entitled "Emotional Intelligence: Why It Can Matter More Than IQ." He summarized the concept of emotional intelligence into five domains. The five domains are:

i) Knowing one's emotions

ii) Managing one's emotions

iii) Motivating oneself

iv) Recognizing and understanding others' emotions

v) Managing others' emotions ${ }^{26}$

The five domains are sometimes referred to as the components or elements of emotional intelligence. A person is said to be emotionally intelligent if he is able to utilize all the five elements or components of emotional intelligence. That is an individual needs to know his/her emotions, control those emotions as a way of motivating oneself. Apart from that it is important that an individual understands other people's emotions and use that understanding or knowledge to manage those other people so as to develop relationship which encourage learning from others. In a learning setting at university level, students should be aware that they are responsible not only for their own learning, but also for the learning of other students. ${ }^{27}$ Thus, the emotional intelligence of students is important so that they identify, assess and make use of not only their emotions but also of their classmates so that the classroom becomes a place for conducive maximum learning.

\section{Students' intelligence and academic achievement}

Academic achievement refers to the goals which teachers or lecturers hope their students are able to reach. In a university setting such goals may

${ }^{26}$ Daniel Goleman, Emotional Intelligence: Why it can matter more than IQ (New York: Bantam Books, 1995).

27 Joyce Bruce, Models of Learning-Tools for Teaching (Buckingham: Open University Press, 2002). 
include matters such as obtaining a passing grade in a particular subject area, for example algebra; to graduate with a certain degree classification. In accomplishing such goals students need to be in the right frame of mind. As such emotions should be identified and utilised accordingly. The students' ability to utilise emotions is important in academic achievement. Many scholars $^{28}$ support this, and furthermore, assert that the skills to identify and manage emotions appear to be major contributors to students' success and avoiding dropping out of university. Thus, it seems awareness and controls of emotions are important for the students' academic success in Algebra or any other area of study.

\section{Algebra teaching and achievement}

Algebra teaching and learning among the first year students at university level is key to teaching and learning of mathematics in its entirety. At many universities algebra is taught in the first term, leaving other branches of mathematics for term two and three. This is so because algebra provides a sound background for the learning of other branches of mathematics. ${ }^{29}$ In fact this is the more reason why algebra is taught earlier than other branches of mathematics because algebra has its roots in both arithmetic and geometry. ${ }^{30}$ It is further acknowledged that algebra has a system of symbols to explain relationships. The symbols used in algebra will have different meanings and interpretations depending on the situation. Therefore, students should take time and effort to familiarize themselves with these symbols and their meanings. From this background, it is clear that the learning of algebra and mastering of the symbols provides a useful foundation for the students to learn the other aspects of mathematics for instance arithmetic, geometry, trigonometry and calculus.

There is need for students to develop positive emotional intelligence towards algebra so that they are able to confidently solve new problems in different situations. Students should believe in themselves and learn to cooperate with other students in order to solve such new problems in new situations. Learning of any concept brings change in the learner. Such learning affects the emotions of the learner either positively or negatively. In

${ }^{28}$ Parker et al., "Assessing Emotional Intelligence.”

${ }^{29}$ Kulbir Singh Sidhu, The Teaching of Mathematics (New Delhi: Sterling Publishers Private Limited, 1995).

${ }^{30}$ Doug French, Teaching and Learning Algebra (New York: Continuum, 2002). 
a university setting, students should know why they feel the way they do towards a learning situation. They need to manage their emotions and appreciate the emotions of those around them. There is need for students to work on assignments in a way that promotes cooperation with and from others. Students need to understand themselves, their friends and their lecturers in order to appreciate each other as important in any given learning situation. Scholars ${ }^{31}$ give us a view of how students and lecturers should relate to each other when they describe education as a social system devoted to developing better human relations, whereby students' needs are met. In this way students are better able to cope with their world of learning. Better human relations help students build a cooperative social environment within the classroom and teach students the skills of negotiation and conflict resolution necessary for democratic problem solving. ${ }^{32}$

\section{Methodology and data collection}

\section{Research design}

This study adopted a correlational descriptive survey research design. In correlational research design, the researcher seeks to establish the degree of relationship between two or more variables..$^{33}$ The variables whose relationship was explored are emotional intelligence and algebraic competences of first year Bachelor of Science in mathematics and science education students who were enrolled in a mathematics and science teacher education programme at the Copperbelt University in Zambia.

\section{Participants}

A total of 143 first years in the academic year 2016/2017 were targeted in the study. The students were enrolled for the Bachelor of Science in mathematics and science education in the School of Mathematics and Natural Sciences in the Department of Mathematics and Science Education. The BSc programme they were pursuing trains science and mathematics secondary school teachers.

31 Jean Dresden Grambs, John C. Carr, and Robert M. Fitch, Modern Methods in Secondary Education, $3^{\text {rd }}$ ed. (New York: Holt, Rinehart and Winston Inc., 1970).

${ }^{32}$ Bruce, Models of Learning.

${ }^{33}$ Louis Cohen, Lawrence Manion, and Keith Morrison, Research Methods in Education, $5^{\text {thed. }}$ (New York: Routledge Falmer, 2004). 
All students were taking the compulsory course MA 120 (First year university mathematics). However, only 107 ( 25 females and 82 males) students fully participated in the study by completing the research instruments designed for the study. Three data collection instruments were employed in this study: the Schutte Self-Report Intelligence Test (SSEIT), Algebra Achievement Test (Grade 12 Level), and the Algebra Achievement Test (University Level).

\section{Measuring emotional intelligence}

In this study emotional intelligence was measured using the 33-item Schutte Self-Report Intelligence Test. This is a self-report test developed by Schutte and her colleagues. ${ }^{34}$ The test measures four factors: expression of self's emotions, understanding of others emotions, regulation of emotions, and utilization of emotions. The items are scored on a 5 point Likert scale (1-Strongly disagree; 2-Disagree; 3-Neither disagree nor agree; 4-Agree; 5-Strongly Agree).

\section{Measuring algebraic competences}

The researcher developed two tests to measure algebraic competences. The first test was an Algebra Achievement Test (Grade 12 Level) developed to assess students' level of competence in Algebra of Grade 12 level. The second test was an Algebra Achievement Test (University Level) developed to assess students' levels of competence in Algebra of first year university level. Both tests included Algebraic topics such as solving of quadratic equations, simplifying expressions, changing subject of the formula, and simultaneous equations among others.

\section{Reliability of instruments}

SSEIT's reliability was calculated using Cronbach's reliability test and Cronbach's alpha was found to be 0.793 (or 0.79) which showed good reliability of the SSEIT.

To calculate the Algebra tests reliability the researcher used the Parallel forms of reliability. This is the reliability test in which two similar tests are

${ }^{34}$ Schutte et al., "Development and validation of a measure of emotional intelligence," Personality and Individual Differences 25 (1998): 167-177. 
given to the same group of participants at different times and the scores obtained in the two tests are correlated. The coefficient of correlation $\mathrm{r}$ was 0.889 (or 0.9) for the Grade 12 level Algebra and $r=0.859$ (or 0.9) for the first year university level Algebra.

\section{Piloting the research instruments}

All three instruments were piloted before being administered to the target group. The researcher selected 20 students (10 females and 10 males) from the population of the main study. Both stratified and systematic random sampling techniques were employed to select the pilot sample. Stratified sampling ${ }^{35}$ involves dividing the population into smaller groups, each containing participants with similar characteristics, for example, group A might contain males and group B, females. Systematic sampling ${ }^{36}$ involves selecting subjects from a population list in a systematic way. For example if from a population of 100 a sample of 20 is required, then every fifth person can be selected, that is $\frac{100}{20}=5$. Piloting of the instruments helped the researcher to know, on average, how long it would take respondents to complete each instrument; and also helped the researcher to check on the clarity of instructions and questions in the instrument. Prior to the pilot test, face validity of the achievement tests was achieved by asking three Algebra experts to critically review and give suggestions to improve the tests. The suggestions from the experts were taken care of by making the necessary changes to the tests. Validity of the SSEIT was assumed as its validity had already been established by the designers. ${ }^{37}$

\section{Data analysis}

Before using any statistical technique to test the hypotheses and answer the research questions, the researcher tested for normality of the three sets of data (Emotional Intelligence, Grade 12 level Algebraic competences and First year university level Algebraic competences) using the Shapiro - Wilk test of normality. For any of the three data sets to be said to be normally distributed the Shapiro - Wilk test $\mathrm{p}-$ value should be above 0.05 . The $\mathrm{p}-$

\footnotetext{
35 Cohen et al., Research Methods in Education.

36 Ibid.

37 Schutte et al., "Development and validation of a measure of emotional intelligence."
} 
values for all the data sets are less than 0.05 (as shown in Table 1 below), indicating that the data sets are not normally distributed.

Table 1

Tests of Normality

\begin{tabular}{|l|c|c|c|c|c|c|}
\hline \multirow{2}{*}{} & \multicolumn{3}{|c|}{ Kolmogorov-Smirnov } & \multicolumn{3}{|c|}{ Shapiro-Wilk } \\
\cline { 2 - 7 } & Statistic & df & Sig. & Statistic & df & Sig. \\
\hline SSEIT & .131 & 107 & .000 & .951 & 107 & .001 \\
\hline Grade12levelalgebratest & .143 & 107 & .000 & .919 & 107 & .000 \\
\hline Firstyearuniversityleveltest & .087 & 107 & .046 & .971 & 107 & .020 \\
\hline
\end{tabular}

a. Lilliefors Significance Correction.

Therefore, the researcher used non-parametric statistical techniques to answer the research questions. The techniques used were: Spearman's Rank Order Correlation (rho) and the Mann-Whitney U Test. The Statistical Package for Social Sciences (SPSS) was used to carry out the different analyses.

\section{Ethical considerations}

Informed consent was obtained from each participant and the purpose of the study was explained to the participants. Confidentiality was assured by using codes instead of names throughout the research.

\section{Findings}

Data for the SSEIT and the two achievement tests were punched into Statistical Package for Social Sciences (SPSS) version 23 for analysis. This section presents the results and findings of the analysis with respect to the research questions.

\section{Descriptives}

Table 2 shows the descriptive statistics of the participants. The age of the participants ranged from 18 years to 26 years with a mean age of about 21 
years old. The participants mean score on emotional intelligence for the participants was 77.72 which was the highest compared to the means of the scores in the two algebra tests.

Table 2

Descriptive Statistics

\begin{tabular}{|l|c|c|c|c|}
\hline & N & Minimum & Maximum & Mean \\
\hline Age & 107 & 18 & 26 & 20.53 \\
\hline Grade12levelalgebratest & 107 & 20 & 100 & 74.50 \\
\hline Firstyearuniversityleveltest & 107 & 0 & 96 & 41.52 \\
\hline SSEIT & 107 & 44 & 95 & 77.72 \\
\hline Valid N (listwise) & 107 & & & \\
\hline
\end{tabular}

\section{First research question}

The first research question sought to establish whether there was any correlation between the Grade 12 level Algebraic competences and the First year university level Algebraic competences as measured by the two Algebra tests. Spearman's Rank Order Correlation (rho) was used to establish whether there was correlation. The results showed that there was a strong positive correlation between the Grade 12 level Algebraic competences and the First year university level Algebraic competences $($ rho $=0.689, p<0.01)$.

\section{Second research question}

The second research question aimed at determining whether there was a significant relationship between first year Bachelor of Science in mathematics and science education students' Grade 12 level algebra test scores and their emotional intelligence scores as measured by the SSEIT. Spearman's Rank Order Correlation (rho) was used to find out whether there was correlation. The co-efficient of correlation was found to be (rho $=-0.226$ ). Since rho is small and negative, it was established that there is no positive significant correlation between emotional intelligence and Grade 12 level Algebraic competences. Table 3 below shows the correlations obtained: 
Table 3

Correlation between Grade 12 Algebra test and Emotional Intelligence

\begin{tabular}{|l|l|l|c|c|}
\hline \multicolumn{2}{|l|}{} & SSEIT & $\begin{array}{c}\text { Grade12levelal- } \\
\text { gebratest }\end{array}$ \\
\hline \multirow{2}{*}{$\begin{array}{l}\text { Spearman's } \\
\text { rho }\end{array}$} & SSEIT & $\begin{array}{l}\text { Correlation } \\
\text { Coefficient }\end{array}$ & 1.000 & -.226 \\
\cline { 3 - 5 } & & $\begin{array}{l}\text { Sig. } \\
(2 \text {-tailed })\end{array}$ &. & .019 \\
\cline { 3 - 5 } & $\mathrm{N}$ & 107 & 107 \\
\cline { 3 - 5 } & Grade12levelalgebratest & $\begin{array}{l}\text { Correlation } \\
\text { Coefficient }\end{array}$ & -.226 & 1.000 \\
\cline { 3 - 5 } & & $\begin{array}{l}\text { Sig. } \\
(2 \text {-tailed) }\end{array}$ & .019 &. \\
\cline { 3 - 5 } & $\mathrm{N}$ & 107 & 107 \\
\hline
\end{tabular}

\section{Third research question}

The third research question sought to establish whether there was any significant correlation between first year Bachelor of Science in mathematics and science education students' university algebra test scores and their emotional intelligence scoresas measured by the SSEIT. The researcher used Spearman's Rank Order Correlation (rho) to find out whether there was any correlation. The co-efficient of correlation was found to be $(\mathrm{rho}=-0.123)$. Since rho is small and negative it was established that there is no positive significant correlation between emotional intelligence and academic achievement in first year university Algebra. Table 4 below shows the correlations obtained:

Table 4

Correlation between University Algebra test and Emotional Intelligence

\begin{tabular}{|l|c|l|c|c|}
\hline \multicolumn{2}{|l|}{} & $\begin{array}{c}\text { Firstyearuniversi- } \\
\text { tyleveltest }\end{array}$ & SSEIT \\
\hline $\begin{array}{l}\text { Spearman's } \\
\text { rho }\end{array}$ & Firstyearuniversityleveltest & $\begin{array}{l}\text { Correlation } \\
\text { Coefficient }\end{array}$ & 1.000 & -.123 \\
\cline { 3 - 5 } & $\begin{array}{l}\text { Sig. } \\
(2-\text {-tailed })\end{array}$ & & .206 \\
\cline { 3 - 5 } & $\mathrm{N}$ & 107 & 107 \\
\hline
\end{tabular}




\begin{tabular}{|l|c|l|c|c|}
\hline \multicolumn{2}{|l|}{} & $\begin{array}{c}\text { Firstyearuniversi- } \\
\text { tyleveltest }\end{array}$ & SSEIT \\
\hline $\begin{array}{l}\text { Spearman's } \\
\text { rho }\end{array}$ & SSEIT & $\begin{array}{l}\text { Correlation } \\
\text { Coefficient }\end{array}$ & -.123 & 1.000 \\
\cline { 3 - 5 } & $\begin{array}{l}\text { Sig. } \\
(2 \text {-tailed })\end{array}$ & .206 &. \\
\cline { 3 - 5 } & $\mathrm{N}$ & 107 & 107 \\
\hline
\end{tabular}

\section{Fourth research question}

The fourth research question: "Is there significant difference between male and female first year Bachelor of Science in mathematics and science education students in their emotional intelligence as measured by the SSEIT?" To answer this research question, the researcher considered the fact that the data was not normally distributed and that there was need to explore differences between males and females on the measure of emotional intelligence. Therefore a non-parametric statistical technique was to be used. The Mann-Whitney U Test (the non-parametric alternative to the t-test for independent samples) was used to analyse the data. As shown in Table 5, the test was set with the null hypothesis (Ho) that the distribution of Emotional Intelligence is the same across categories of Gender while the alternative hypothesis $\left(H_{\mathrm{A}}\right)$ was that the distribution of emotional intelligence was not the same across categories of Gender. The Mann-Whitney U Test indicates that the Null Hypothesis: the distribution of Emotional Intelligence is the same across categories of Gender should be rejected since $p=0.004$ which is less than the set significance level of 0.05 . Therefore the hypothesis $\left(H_{\mathrm{A}}\right)$ that

Table 5

Emotional Intelligence and gender

Hypothesis Test Summary

\begin{tabular}{|clll|}
\hline \multicolumn{1}{|c|}{ Null Hypothesis } & \multicolumn{1}{c|}{ Test } & Sig. & Decision \\
\hline $\mathbf{1}$ & $\begin{array}{l}\text { Independent- } \\
\text { The distribution of SEIT is the same } \\
\text { across categories of Gender. }\end{array}$ & $\begin{array}{l}\text { Samples } \\
\text { Mann- } \\
\text { Whitney U } \\
\text { Test }\end{array}$ & $.004 \begin{array}{l}\text { Reject the } \\
\text { null } \\
\text { hypothesis. }\end{array}$ \\
\hline
\end{tabular}

Asymptotic significances are displayed. The significance level is .05 . 
the distribution of Emotional Intelligence was not the same across categories of Gender is accepted. Results indicate further that female students have higher emotional intelligence levels (Mean rank $=69.70$ ) compared to their male counterparts ( Mean rank $=49.21$ ).

\section{Discussion}

The study was set out to address four research questions: to examine if there is any correlation between Grade 12 level Algebraic competences and First year university level Algebraic competences, to find out if there is a significant relationship between first year Bachelor of Science in mathematics and science education students' Grade 12 level algebra test scores and their emotional intelligence scores as measured by the SSEIT, to find out if there is a significant relationship between first year Bachelor of Science in mathematics and science education students' university algebra test scores and their emotional intelligence scores as measured by the SSEIT, and to establish if there a significant difference between male and female first year Bachelor of Science in mathematics and science education students in their emotional intelligence as measured by the SSEIT.

From the research findings it is clear that the students Grade 12 Algebraic competences correlate with First year university level Algebraic competences. This indicates that building on prior knowledge is an important principle for educators. The topics which were in the two algebra tests were based on the same topic areas; they only differed in terms of their levels of difficulty. There were questions on linear equations, simultaneous equations, inequalities, word problems in both tests. The correlation may be explained in the context of students having competences in first university algebra because of their experiences in Grade 12 level Algebra.

In considering the second and third research questions, the study has established that there is no positive significant correlation between algebraic competences and emotional intelligence. These findings are consistent with findings of some earlier researchers. For instance Nor et al. ${ }^{38}$ conducted a study on the relationship between emotional intelligence and mathematical competence among secondary school students. It was found that there was no relationship between students' emotional intelligence and their mathematical

${ }^{38}$ Nurul Adibah Khairiyah Mohd Nor, Zaleha Ismail, and Yudariah Mohammad Yusof, "The Relationship Between Emotional Intelligence and Mathematical Competency Among Secondary School Students," Journal on Mathematics Education 7, no. 2 (2016): 91-100. 
competence. Although the study focused on secondary school students, the variables considered were emotional intelligence and mathematical competence of which algebraic competence was part.

A study conducted at an Engineering institution explored the relationship between different factors of emotional intelligence and academic performance of engineering students. ${ }^{39}$ The Schutte Emotional Intelligence Test was used to measure emotional intelligence while students' academic performance was taken from academic records. A total of 177 students participated in the study and the study revealed that academic performance of engineering students in that institution was independent of factors of emotional intelligence and also of total emotional intelligence.

Another study ${ }^{40}$ that revealed no statistically significant link between academic achievement and emotional intelligence is the study that investigated the effect of emotional intelligence and academic procrastination on academic achievement of students in two Nigerian Universities.One hundred respondents participated in the study. Two instruments were adapted for the study: the Emotional Intelligence Scale and Academic Procrastination Scale. Data obtained was analyzed using Pearson Product Moment Correlation (PPMC) and t-tests. Findings revealed that there was no significant relationship between emotional intelligence and academic achievement of students and there was no significant relationship between academic procrastination and academic achievement.

From studies cited above it is clear that while emotional intelligence may be one of the factors affecting students' academic achievement, it should be noted that other factors are equally at play. Another matter of consideration is that of the sample size in this study (107); in many of the studies cited where emotional intelligence seemed to impact on academic achievement positively, the sample sizes were greater than this ( 150 or higher).

An additional issue of consideration is that in nearly all the studies that the researcher revealed where emotional intelligence was found to significantly affect academic achievement positively, academic achievement was measured by the use of multiple choice tests (in the case of one test) or Grade Point Average (GPA) in the case of many subjects. In the case of multiple choice questions, all the questions have a fixed list of answer

39 Rama V.Devi and Lakshmi P. Narayanamma, “Academic Achievement in Engineering: Does Emotional Intelligence Matter?," International Business Management Journal 8, no. 2 (2014): 85-92.

${ }^{40}$ Eni-Olorunda Tolu and Adesokan Adedayo, "Emotional Intelligence, Academic Procrastination and Academic Achievement in Two Tertiary Institutions in South-Western Nigeria," Gender and Behaviour Journal 13, no. 1 (2015). 
options and the data the researchergets back is limited to the choices the researcher provides. The multiple choice questions in many instances is more or less like the Likert type questions which also have fixed answer options. In this study academic achievement was measured by an algebra test in which participants were required to show their working instead of just the final solutions. There were marks given for the method as opposed to the multiple choice case where only the final answer mattered. In the case of the GPA, performance from several subjects or courses is averaged to come up with one grade. The advantage of this grading being that for a student sitting for tests in say six courses (as is the case at Copperbelt University) poor performance in one or two courses may be offset by very good performance in the remaining four courses, hence a good overall GPA. In this study the participants' mean achievement in Algebra was (41.52\%) and this was below thepass mark of $50 \%$ for Copperbelt University. This poor performance could be compensated by good performance in other courses for some students in the case of a GPA.

In considering the fourth objective the study has established that among the first year Bachelor of Science in mathematics and science education students, females have higher emotional intelligence compared to males. This means female students in this study are better able to identify their emotions, those of others and are better able to manage relationships. Other researchers have found similar results to this study in the area of emotional intelligence and gender. ${ }^{41}{ }^{42}$

\section{$X$. Conclusion and recommendations}

This study has revealed that there is a significant positive correlation (0.689) between students' Grade 12 algebraic competences and their first year university algebraic competences. This means that participants who failed the Grade 12 level based Algebra test also failed the university level based Algebra test. Similarly, those with good Grade 12 level Algebra competences generally exhibited good first year university level Algebra competences.

There is no significant relationship between students algebraic competences and their emotional intelligence levels. Therefore, low achievement levels in

${ }^{41}$ Sangita, Biswas and Surekha Invalli, "A Study on the Relationship between Gender and Emotional Intelligence,”Journal of Exclusive Management Science 5, no. 5 (2016).

${ }^{42}$ Maryam, Meshkat and Reza Nejati, "Does Emotional Intelligence Depend on Gender? A Study on Undergraduate English Majors of Three Iranian Universities," SAGE journal (2017): 1-8. 
first year university Algebra (and mathematics in general) at Copperbelt University cannot be traced back to students' lack of emotional intelligence. Students have higher levels of emotional intelligence as already indicated, however, there is no positive correlation with their algebraic competences. Possesion of high levels of emotional intelligence did not necessarily translate into acqusition of algebraic competences and success in first year mathematics.

It has been established that there is a significant difference between male and female first year Bachelor of Science in mathematics and science education students in their emotional intelligence as measured by the SSEIT. The females exhibited higher levels of emotional intelligence than their male counterparts. A number of studies attest to the fact that females are generally more emotionally intelligent than males. ${ }^{43,44,45,46}$

Future research may consider the relationship between achievement in first year mathematics and other factors, such as, learning resources, class sizes, lecturers' attitude, student's attitude, parental background among others. This is in order to establish factors influencing the low academic achievement levels of first year students in mathematics.

\section{Bibliography}

Adigwe, Joseph C. "Emotional Intelligence and Problem-Solving Achievement of Chemistry Students."Journal of Science, Technology \& Education 3, no. 1 (2015): 80 - 95.

Al Asmari, AbdulRahman. "Emotional Intelligence and Academic Achievement: A Comparative, Gender-Based Study of Undergraduate English Language Learners in Saudi Arabia." Journal of Education and Practice 5, no. 6 (2014): 178-190.

Biswas, Sangita, and Surekha Invalli. "A Study on the Relationship between Gender and Emotional Intelligence." Journal of Exclusive Management Science 5, no. 5 (2016).

Bruce, Joyce. Models of Learning-Tools for Teaching. Buckingham: Open University Press, 2002.

${ }^{43}$ AbdulRahman Al Asmari, "Emotional Intelligence and Academic Achievement: A Comparative, Gender-Based Study of Undergraduate English Language Learners in Saudi Arabia," Journal of Education and Practice 5, no. 6 (2014).

${ }^{44}$ Irum Hayat et al., "Gender Influence On Emotional Intelligence And Professional Development Among Secondary School Teachers," Sci.Int.(Lahore) 28, no. 1 (2016): 645-652.

45 Shumaila Shehzad and Nasir Mahmood, "Gender Differences in Emotional Intelligence of University Teachers," Pakistan Journal of Social and Clinical Psychology 11, no.1 (2013): 16-21.

${ }^{46}$ Al- Sahafi Faisal and Mohd Zuri Bin Ghani, "Gender Difference on Emotional Intelligence Elements towards Academic Achievement among Gifted Students In Saudi Arabia," International Journal of Research In Social Science 5, no. 2 (2015). 
Chen, Yoke Theing, and Chooi Seong .L. "Personality Traits, Emotional Intelligence and Academic Achievements of University Students."American Journal of Applied Psychology 4, no. 3 (2015): 39-44.

Chew, Boon How, AzharMd Zain, and Faezah Hassan. "Emotional intelligence and academic performance in first and final year medical students: a cross-sectional study." BMC Medical Education 13 (2013):44.

Chirayath, Susan and Nancy G. Elizabeth. "Influence of Emotional Intelligence on Learning Styles-An Exploratory Study on Management Students." Journal of Business Management \& Social Sciences Research 2, no. 3 (2013): 14 - 23.

Cohen, Louis, Lawrence Manion and Keith Morrison. Research Methods in Education. 5 $^{\text {th }}$ d.. New York: Routledge Falmer, 2004.

Devi, Rama V., and Lakshmi P. Narayanamma. "Academic Achievement in Engineering: Does Emotional Intelligence Matter?” International Business Management Journal 8, no. 2 (2014): 85-92.

Eni-Olorunda, Tolu, and Adesokan, Adedayo. "Emotional Intelligence, Academic Procrastination and Academic Achievement in Two Tertiary Institutions in South-Western Nigeria." Gender and Behaviour Journal 13, no. 1 (2015).

Faisal Al- Sahafi, and MohdZuri Bin Ghani, "Gender Difference on Emotional Intelligence Elements towards Academic Achievement among Gifted Students In Saudi Arabia” International Journal of Research In Social Sciences 5, no. 2 (2015).

Fayombo, Grace A. "Relating emotional intelligence to academic achievement among university students in Barbados." The International Journal of Emotional Education 4, no. 2 (2012): 43 -54.

French, Doug. Teaching and Learning Algebra. New York: Continuum, 2002.

Goleman, Daniel. Emotional Intelligence: Why it can matter more than IQ. New York: Bantam Books, 1995.

González, Julia, and Robert Wagenaar, eds. Tuning Educational Structures in Europe II. Universities' Contribution to the Bologna Process. Bilbao: Universidad de Deusto, 2005.

Grambs, Jean D., John C. Carr, and Robert M. Fitch. Modern Methods in Secondary Education. $3^{\text {rd }}$ ed. New York: Holt, Rinehart and Winston Inc., 1970.

Hahn, Karola, and Damtew Teferra. "Tuning as Instrument of Systematic Higher Education Reform and Quality Enhancement: The Africa Experience." Tuning Journal for Higher Education 1, no. 1 (2013): 127-163.

Hayat, Irum, Tahira Bibi, and MamonahAmbreen."Gender Influence on Emotional Intelligence and Professional Development among Secondary School Teachers."Sci.Int.(Lahore) 28, no.1 (2016): 645-652.

Kolachina, Aruna. "Impact of Emotional Intelligence on Academic Achievements of Expatriate College Students in Dubai."International Journal of Social Science and Humanities Research 2, no. 2 (2014).

Leung, Frederick K. S., Kyungmee Park, and Derek Holton.Algebra Teaching around the World. Rotterdam: Sense Publishers, 2014.

McPheat, Sean. Emotional Intelligence. London: Ventus Publishing Apps, 2010. 
Meshkat, Maryam, and Reza Nejati, "Does Emotional Intelligence Depend on Gender? A Study on Undergraduate English Majors of Three Iranian Universities."SAGE journal (2017): 1- 8.

Ministry of Education (MoE). "O” Level Mathematics Syllabus (Grades 10-12). Lusaka: Curriculum Development Centre, 2012.

Mishra, Poonam. "A Study of the Effect of Emotional Intelligence on Academic Achievement of Jaipur Senior Secondary Students."International Journal of Educational Research and Technology 3, no.4 (2012)

Nor Mohd, NurulAdibahKhairiyah, Zaleha Ismail, and Yudariah Mohammad Yusof. "The Relationship Between Emotional Intelligence and Mathematical Competency Among Secondary School Students." Journal on Mathematics Education 7, no. 2 (2016): 91-100.

Parker, James D. A., Donald H. Saklofske, and Con Stough, eds. Assessing Emotional Intelligence - Theory, Research, and Applications. New York: Springer, 2009.

Prabha M., Rosalind. "Emotional intelligence as a correlate of academic achievement among first year degree students in Puducherry."International Journal of Research In Social Sciences 3, no. 6 (2015): 259-263.

Sánchez, A. Villa, and Manuel Poblete Ruiz, eds. Competence -based learning: A proposal for the assessment of generic competences. Bilbao: University of Deusto, 2008.

Schutte, Nicola S., John M. Malouff, Lena E. Hall, Donald J. Haggerty, Joan T. Cooper, Charles J. Golden, and Liane Dornheim. "Development and validation of a measure of emotional intelligence." Personality and Individual Differences 25 (1998): 167-177.

Serrat, Olivier. Understanding and Developing Emotional Intelligence. Washington, DC: Asian Development Bank, 2010.

Shehzad, Shumaila, and Nasir Mahmood."Gender Differences in Emotional Intelligence of University Teachers."Pakistan Journal of Social and Clinical Psychology 11,no.1 (2013): 16-21.

Walsh-Portillo, Joyce G. "The Role of Emotional Intelligence in College Students' Success.” PhD diss., Florida International University, 2011.

Yahaya, Azizi, Ng Sar Ee, Junaidah Bachok, Noordin Yahaya, Yusof Boon, Shahrin Hashim, and Goh Mo Lee. "The Impact of Emotional Intelligence Element on Academic Achievement.” Journal of Archives Des Sciences 65, no. 4 (2012).

\section{About the author}

ALLAN MUSONDA (allanmusondak@yahoo.co.uk) is Lecturer (II) of Mathematics Education at the Copperbelt University in Zambia. He has been teaching Mathematics at college and university levels since 2002; with special interest in Algebra learning and teaching in secondary schools and tertiary institutions, as well as in the role of emotions in mathematics learning. Musonda holds a Master of Education in Mathematics Education. 


\title{
Algebraic competences and emotional intelligence of first year Bachelor of Science in Mathematics and Science Education students at the Copperbelt University in Zambia
}

\author{
Allan Musonda
}

\section{Copyright}

Copyright for this article is retained by the Publisher. It is an Open Access material that is free for download, distribution, and or reuse in any medium only for non-commercial purposes; provided any applicable legislation is respected, the original work is properly cited, and any changes to the original are clearly indicated. 